\section{Herzinfarktrisiko: EU-Grenzwerte für Stickstoffdioxid zu locker?}

\begin{abstract}
Erhöhte Stickstoffdioxid- und Feinstaubbelastungen scheinen einer belgischen Studie zufolge mit einer erhöhten Herzinfarktrate assoziiert zu sein. Beim ESC-Kongress nahm man diese Untersuchung als Anstoß, die von der EU möglicherweise zu locker festgelegten Schadstoffgrenzwerte zu überdenken.
\end{abstract}

$\mathrm{D}$ ie EU hat ihre Feinstaub- und Stickstoffdioxid-Grenzwerte womöglich zu locker festgelegt. Darauf deutet eine belgische Untersuchung hin, die von Dr. Jean-Francois Argacha vom Universitätsklinikum Brüssel auf einer Pressekonferenz des ESC-Kongresses 2015 in London vorgestellt wurde. Argacha und sein Team haben die Assoziation zwischen kurzfristigen Feinstaub- und gasförmigen Schadstoffbelastungen und der STEMI-Rate innerhalb Belgiens untersucht.

Demnach erhöhte ein Anstieg von $10 \mu \mathrm{g} / \mathrm{m}^{3}$ PM2,5-Konzentration, also Feinstaub-Partikel mit einem Durchmesser $\leq 2,5 \mu \mathrm{m}$, das Risiko für einen STEMI um 2,8\% - und zwar bereits innerhalb eines Tages, an dem die erhöhte Belastung gemessen wurde. Noch deutlicher jedoch fiel die Risikoerhöhung mit 5,1\% $10 \mu \mathrm{g} / \mathrm{m}^{3}$ im Falle pro

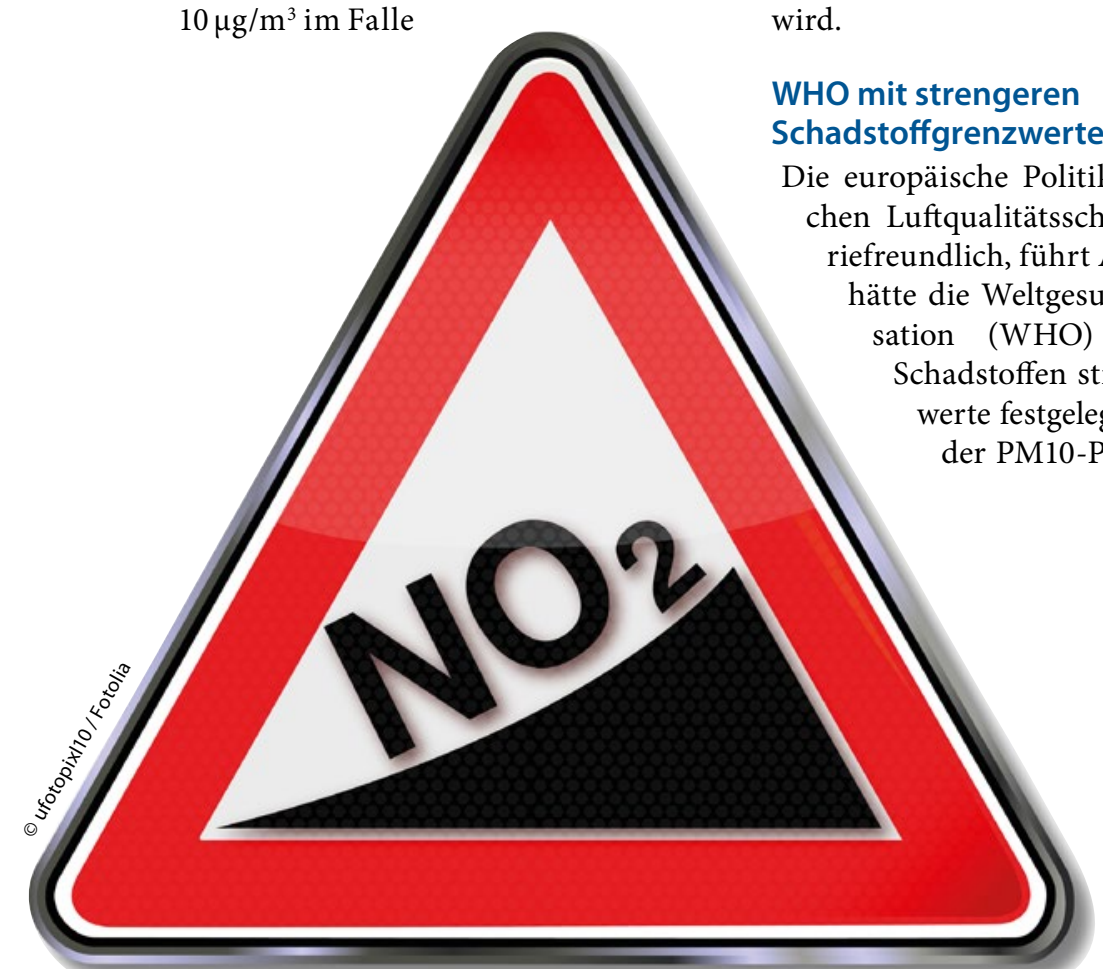

Die $\mathrm{NO}_{2}-$ Belastung ist in Deutschland besonders hoch. nen sie statt $40 \mu \mathrm{g} / \mathrm{m}^{3}$, wie es die EU vorgebe, $25 \mu \mathrm{g} / \mathrm{m}^{3}$ empfehle. „Vielleicht ist es an der Zeit, dass die EU ihre Empfehlungen entsprechend anpasst", gab Argacha zu bedenken.

Die Luftverschmutzungen in Echtzeit hat sein Forscherteam aus Messwerten der „Belgian Interregional Environment Agency“ (IRCL-CELINE) für alle belgischen Regionen errechnet. Diese Werte wurden mit 11.428 Patientenfällen, die zwischen 2009 und 2013 aufgrund von STEMI in die Klinik eingewiesen und im „Belgian Interdisciplinary Working Group on Acute Cardiology (BIWAC) STEMI“-Register dokumentiert worden waren, in Beziehung gesetzt.

\section{Assoziation fand}

sich nur bei Männern

Die in diesem Zeitraum beobachtete Assoziation zwischen $\mathrm{NO}_{2}$ - und PM2,5-Erhöhungen und steigenden STEMI-Raten fand sich allerdings nur bei Männern. Dies könne an der Unterrepräsentierung der Frauen liegen, lautet eine Erklärung Argachas, sie machten nämlich weniger als $25 \%$ der Studienpopulation aus. Andererseits gebe es die Hypothese, dass Männer auf Luftverschmutzung hinsichtlich ihres Blutdrucks, arteriellen Gefäßsteifigkeit und Herzfrequenz-Variabilität sensibler reagierten. Einschränkend $\mathrm{zu}$ erwähnen ist zudem, dass zwischen einer Luftverschmutzung und der STEMI-assoziierten Sterblichkeit kein Zusammenhang gefunden wurde.

Gleichwohl waren sich die Diskutanten der Pressekonferenz einig, dass ein verstärktes politisches Engagement für eine bessere Luftqualität wichtig sei. Denn der Einzelne könne schlechte Luft nur schwer meiden.

Prof. Oscar Franco Duran aus Rotterdam stellte in London die von der ESC zusammen mit der „European Association for Cardiovascular Prevention and Rehabilitation“ (EACPR) und dem „European Heart Network" (EHN) ins Leben gerufene Kampagne „Environment $\&$ the Heart" vor. Mit dieser Kampagne soll das Bewusstsein in der Bevölkerung für die Wechselwirkung von Umwelt und Herzgesundheit gestärkt und politische Umweltschutz-Aktionen angeregt werden.

Veronika Schlimpert 